\title{
ОСОБЕННОСТИ ТРЕВОЖНОСТИ ЛИЧНОСТИ У ДЕТЕЙ С РАЗЛИЧНЫМ ПИЩЕВЫМ ПОВЕДЕНИЕМ
}

\section{PECULIARITIES OF PERSONAL ANXIETY IN CHILDREN WITH VARIOUS EATING BEHAVIOR}

\section{E. Bakaeva}

T. Pilishvili

Summary: This work is devoted to the study of the characteristics of personality anxiety in adolescent girls with different eating behaviors and the causes of eating disorders in adolescents. Referring to the scientific works of various authors in relation to the problem of eating disorders, one can find a lot of information, but since this topic has not been fully studied, there is no single view that could reflect the full deep picture of personal experiences and the reasons for their formation in adolescents.

Keywords: eating disorder, eating disorder, eating disorder, deviant eating behavior, eating behavior, causes of eating disorder, peculiarities of personality anxiety in eating disorder.
В последнее время проблема нарушений пищевого поведения становится всё более актуальной. Особенно важны вопросы пищевого поведения в подростковом возрасте, когда активно формируется отношение к себе и своему телу, происходит включение в мир межличностных отношений и повышение значимости внимания со стороны противоположного пола. Именно на этот возрастной период приходится основная масса нарушений пищевого поведения, которые, при отсутствии адекватной коррекции, влияют на дальнейшее развитие личности.

Такие особенности, как неудовлетворенность собой, негативные установки по отношению к окружающим и выраженный перфекционизм, характерные для лиц с нарушениями пищевого поведения, оказывают существенное влияние на эмоциональную сферу детей с нарушениями пищевого поведения, в частности, способствуя повышению тревоги, которая закрепляется и становится стабильной чертой личности. В связи с этим является актуальным выявление взаимосвязей характеристик тревожности и особенностей эмоционально-личностной сферы у девочек пубертатного возраста с нарушениями пищевого поведения.

Пубертатный возраст обычно описывают как особенно эмоциональный период, подростки становятся легко возбудимыми, ранимыми, отмечается частая смена настроения. Это возраст глубоких и ярких переживаний,
Бакаева Елена Юрьевна

Российский Университет Дружбы Народов, г. Москва bakayeva_yelena@inbox.ru

Пилишвили Татьяна Сергеевна К.nсх.н., дочент, Российский Университет Дружбы Народов, г. Москва pilishvili-ts@rudn.ru

Аннотация: Настоящая работа посвящена исследованию особенностей тревожности личности у девочек пубертатного возраста с различным пищевым поведением и причинам возникновения нарушения пищевого поведения у подростков. Обращаясь к научным работам различных авторов в отношении проблемы расстройства питания, можно найти множество информации, но ввиду того, что данная тема до конца так и не изучена, нет единого взгляда, который смог бы отразить полную глубинную картину личностных переживаний и причин их формирования у подростков.

Ключевые слова: нарушение пищевого поведения, нарушение питания, расстройство пищевого поведения, девиантное пищевое поведение, пищевое поведение, причины расстройства пищевого поведения, особенности тревожности личности при нарушении пищевого поведения.

аффективных реакций, страхов насмешек и шаткой самооценки.

A.М. Прихожан в своей работе описала причины и проявления тревожности у детей различных возрастов. Ею приведены данные эксперимента реагирования детей подросткового возраста в условиях экзамена. Было отмечено ряд феноменов:

1. Поведенческие реакции - двигательная активность (теребит предметы в руках, крутит волосы, трет пальцы, кончик носа, грызет карандаш)

2. Вегетативные проявления - учащенный пульс, сдавленность дыхания, потливость, нарушение сна и питания;

3. Эмоциональные реакции - страх неудачи, провала, желание убежать, испариться, чувство одиночества и беспомощности, стыда и вины, неполноценности. (А.М. Прихожан, 2000, с.71)

3. Фрейд, рассматривая феномен тревоги, привел характерные ситуации риска, актуальные в развитии ребенка:

- утрата объекта любви (матери, опекуна, значимого взрослого);

- страх телесного наказания (кастрации);

- страх быть покинутым (брошенным).

Базальной потребностью пубертатного возраста является понимание. Чтобы подросток был откровенен и 
открыт, необходимо удовлетворение его потребностей в течение более ранних периодов формирования его личности. (Е.Л. Солдатова, Г.Н. Лаврова, с.161)

В противном случае ребенок становится замкнутым, скрытным и, как следствие, одиноким. Он остается один на один со своими тревогами и страхами, которые при выраженных их формах способны найти свое отражение в нарушениях пищевого поведения.

Под пищевым поведением понимают совокупность следующих факторов:

- сформированную привычку, связанную с процессом питания;

- место еды и процесса приема пищи в системе ценностей человека;

- формирование своего тела, а также восприятие и отношение к его образу.

Различают гармоничное и девиантное пищевое поведение.

В качестве основных нарушений пищевого поведения выделяют 3 основных типа:

- экстернальное;

- эмоциогенное;

- ограничительное. (Малкина-Пых, 2007).

Учитывая, что человек имеет биологическую, психологическую и социальную природу, рассмотрим потребности в питании индивида с точки зрения следующих биопсихосоциальной модели:

1. Человек - биологический организм, который имеет физиологические потребности. В рамках данного фактора пищевое поведение можно рассмотреть, как стратегии удовлетворения голода с целью поглощения энергии, реализации химических процессов в организме и достижения гомеостаза, фактически речь идет о поддержании жизни.

Врачи, рассматривая феномен расстройства питания, отмечают метаболические нарушения, а также ссылаются на сходства с точки зрения генетического кода - наличие у пациентов с ограничительным пищевым поведением определенного гена (HTR2A-ген серотонинового рецептора 5-НТ2А и ген мозгового нейтрофического фактора (BDNF) (А.О. Кибитов, Г.Э. Мазо, 2016);

2. Человек - организм, имеющий психику. С точки зрения этого аспекта, пищевое поведение можно рассмотреть со стороны психологического процесса. Потребность в безопасности и потребность в удовлетворении тонко дополняют друг друга. Быть накормленным, быть любимым, быть в безопасности - тождественные понятия.

Жадность, ревность, зависть - желание обладать, поглощать, вызывают бессознательные агрессивные импульсы, подавление которых приводит к возникновению чувства вины и нужды в наказании.

Следовательно, прием пищи или отказ от него может быть реакцией на радость или тревогу, наградой или наказанием, желанием жить или умереть.

3. Человек - социальное существо. В данном контексте прием пищи является частью общения, формирования межличностных отношений, менталитета индивида, а также отражением религиозных взглядов. Прием пищи или отказ от него отражает стремление к или уход от коммуникации, контактов, отношений.

Большинство современных ученых считают, что только совокупность всех трех факторов приводит к нарушению питания.

В отношении психологических причин формирования девиантных форм пищевого поведения можно выделить следующие явления:

1. чувство непереносимой вины и агрессии;

2. стремление к чувству власти и контроля;

3. крик о помощи;

4. уход от женственности и отказ от взросления;

5. выстраивание своих границ;

6. протестное поведение;

7. страх разрыва симбиотической связи с матерью;

8. амбивалентное отношение к половой роли;

9. страх половых отношений и беременности;

10. уход от контактов.

Нами было проведено исследование, целью которого является изучение особенностей тревожности личности у девочек пубертатного возраста с различным пищевым поведением.

Данная работа базируется на предположении, что особенности тревожности и эмоционально-личностной сферы различаются у девочек пубертатного возраста с различным пищевым поведением. Также мы предположили, что существуют взаимосвязи тревожности и характеристик эмоционально-личностной сферы, специфичные для девочек пубертатного возраста с различным пищевым поведением.

В исследовании приняли участие 3 группы респондентов:

- 21 человек - девочки пубертатного возраста с ограничительным пищевым поведением (диагностирована нервная анорексия), ИМТ $\leq 17,5$;

- 20 человек - девочки пубертатного возраста с экстернальным и эмоциогенным типом пищевого поведения, 20,5 $\leq$ ИМТ $\leq 32$;

- 20 человек - девочки с гармоничным типом пище- 
вого поведения, $18,5 \leq$ ИМТ $\leq 25$.

В работе были использованы следующие психодиагностические методики:

1. Шкала Ч. Спилбергера - Ю. Ханина для диагностики тревожности;

2. Торонтская шкала алекситимии TAS-26 (Г.Тейлор, адаптация НИИ Бехтерева);

3. Опросник способов совладающего поведения (копинг-стратегии) Р. Лазаруса, С. Фолкман (адаптация Т.Л. Крюковой, Е.В. Куфтяк, М.С. Замышляевой;

4. Шкала ригидности Г. Айзенка;

5. Шкала самоотношения В. Столина-С. Пантилеева;

6. Шкала депрессии А. Бека;

7. Шкала перфекционизма Н. Гаранян и А. Холмогоровой.

А также методы математико-статистической обработки данных (сравнительный анализ - U-критерий Манна Уитни, Н Критерий Крускала-Уоллиса, корреляционный анализ - коэффициент ранговой корреляции Спирмена).

Были выявлены следующие особенности:

- Девочки с ограничительным пищевым поведением имеют высокий уровень ситуативной и личностной тревожности, что характеризует актуальное эмоциональное состояние как переживание напряжения и психологического дискомфорта, а также отражает склонность личности реагировать тревогой на различные жизненные ситуации.

У этой группы подростков был выявлен средний уровень алекситимии, что говорит о наличии сложностей при распознавании и выражении своих переживаний.

Отмечается преобладание стратегий бегства, самоконтроля, что демонстрирует стремление к избеганию проблем и контролю своих эмоций и поведения.

В сравнении с другими группами детей, для них в наибольшей степени характерны копинг-стратегии принятия ответственности и бегства. Вероятно, данный факт можно связать со склонностью к самообвинению, сформированному как реакция на несоответствие определенным идеалам, они могут возлагать всю вину за проблему на себя, не осознавая вклада в неё других людей или обстоятельств.

У этой группы респондентов, в сравнении с другими двумя группами подростков, отмечается наиболее выраженная ригидность, на основании чего можно предположить, что психическая ригидность является одной из основ для формирования нарушений пищевого поведения - предпочтение определенных пищевых привычек закрепляется и не поддаётся коррекции на фоне высокой ригидности.

Стоит отметить высокий уровень депрессии, в частности ее соматическую симптоматику, что можно связать с состоянием истощения у данной группы подростков.

Были выявлены проблемы с отношением к себе, проявляющиеся в неадекватной самооценке - заниженной ее форме.

У девочек в данной группе наблюдается выраженное стремление к достижению совершенства в деятельности, во многих случаях доходящее до патологического.

Также нами было отмечено, что у девочек с ограничительным пищевым поведением ситуативная тревога положительно коррелирует с копинг-стратегией положительной переоценки ( $r s=0,528, p \leq 0,014)$ и отрицательно - с самоинтересом ( $r s=-0,540, p \leq 0,012)$.

Вероятно, это связано с тем, что актуальная ситуация психологического исследования вызывает стремление показать себя с наилучшей стороны в большей степени у тех девочек, которые направлены на личностный рост и оценивают трудности положительно.

Усматривается взаимосвязь, чем выше у девочек с ограничительным пищевым поведением ситуативная тревога, тем меньше у них проявляется интерес по отношению к себе, своим мыслям и переживаниям. Вероятно, в случае высокой актуальной тревоги, активность девочек направляется на предотвращение возможных неудач, т.е. во внешний мир, в то время как своему субъективному состоянию внимание не уделяется.

Личностная тревожность у девочек этой группы положительно коррелирует со стратегиями самоконтроля ( $\mathrm{r}=0,496, \mathrm{p} \leq 0,022)$ и принятия ответственности $(r s=0,525, p \leq 0,014)$, и отрицательно - с самообвинением

$$
(r s=-0,475 p \leq 0,030) \text {. }
$$

Усматривается взаимосвязь - чем больше у подростков этой группы выражена личностная предрасположенность к реакциям тревоги, тем более они склонны к высокому контролю эмоций и поведения в сложной ситуации. Вероятно, девочки с высокой тревожностью чрезмерно контролируют себя, т.к. боятся возможных неудач, которые воспринимаются как угроза образу «Я».

Также нами было отмечено, что девочки с выраженной личностной тревожностью склонны в сложных ситуациях к переоценке своей роли в их возникновении и самообвинению. Можно предположить, что девочки с высокой личностной тревожностью отличаются повы- 
шенным чувством личной ответственности и интернальным локусом контроля, в результате чего все неудачи они предписывают исключительно себе.

Кроме того, личностная тревожность у подростков данной группы сочетается с низким самообвинением. Вероятно, самообвинение представляет собой критичное отношение к себе, подразумевающее низкую самооценку, в результате чего меньше ощущается внешняя угроза образу «я», которая, как правило, и является причиной тревожности.

- Девочки с эмоциогенным и экстернальным пищевым поведением имеют высокий уровень ситуативной и личностной тревожности, что дает основания охарактеризовать актуальный эмоциональный фон насыщенным переживанием напряжения и психологического дискомфорта, а также склонность личности к тревожным реакциям.

Высокий уровень алекситимии говорит о наличии существенных затруднений в распознавании и выражении своих чувств.

В данной группе респондентов преобладают стратегий бегства и самоконтроля. Следовательно, в сложных ситуациях они склонны избегать решения проблем и чрезмерно контролировать свои эмоции и поведение, в то время как преодоление проблемы через снижение её значимости им не характерно.

Стоит также отметить, что эта группа подростков чаще других использует копинг-стратегию конфронтации. Данный факт можно связать с тем, что у девочек с эмоциогенным типом пищевого поведения конфронтация обусловлена высокой импульсивностью, которая наблюдается при выраженной эмоциональной реактивности на события внешнего мира.

У этой группы детей более всего выражена тревожность, алекситимия, депрессия и её когнитивно-аффективная симптоматика, а также перфекционизм.

В этой группе так же преобладают девочки, имеющие негативные особенности самоотношения - завышенную самооценку.

Большинство исследованных в этой группе имеют в значительной степени выраженные симптомы, характерные для депрессивных расстройств. Можно предположить, что именно негативные эмоции стимулируют переедание у этих детей.

Также отмечается средний уровень перфекционизма, что характеризует этих подростков как людей с высоким уровнем стремления к достижению высоких результатов

\section{в деятельности.}

Нами было отмечено, что у девочек с эмоциогенным и экстернальным пищевым поведением ситуативная тревога положительно взаимосвязана с самообвинением ( $r s=0,481, p \leq 0,032)$, а личностная тревожность отрицательно коррелирует с конфронтацией ( $\mathrm{rs}=-0,445$, $\mathrm{p} \leq 0,049)$.

Усматривается взаимосвязь - чем выше у девочек данной группы уровень актуальной тревоги, тем больше у них выражено самообвинение. Вероятно, самообвинение у этих детей является демонстративной реакцией, возникающей в социальных ситуациях и направленной на поиск поддержки от окружающих, и за этой реакцией скрывается неуверенность в себе, чувствительность к критике и высокая тревога.

Можно предположить, что у девочек этой группы высокая личностная тревожность сочетается с низкой склонностью к конфронтации в стрессовых ситуациях. Вероятно, эта группа детей при высокой тревожности отличается чрезмерным самоконтролем своего поведения, который не позволяет им активно действовать в ситуациях стресса, стимулируя пассивную позицию в сложных ситуациях.

- Девочки с гармоничным пищевым поведением имеют низкий уровень ситуативной и умеренный уровень личностной тревожности. Следовательно, актуальное эмоциональное состояние не характеризуется как тревожное, а текущая ситуация воспринимается безопасной. Им характерен средний уровень личностной предрасположенности к реакциям тревоги.

Низкий уровень алекситимии говорит о высокой способности распознавать и выражать свои переживания.

Было установлено преобладание стратегий планирования решения проблемы и самоконтроля, что свидетельствует о том, что в сложных ситуациях они стремятся найти реальный выход из положения и контролировать свои эмоции, при этом может наблюдаться недооценка своего вклада в возникновение проблемы.

Стоит отметить, что им характерно неадекватное отношение к себе, заключающееся в неадекватно завышенной оценке своих качеств и способностей.

У большинства девочек с гармоничным пищевым поведением не выявлено депрессивных симптомов.

Данная группа подростков отличается средним уровнем перфекционизма, что указывает на наличие у них стремление к достижению наивысших результатов дея- 
тельности, не доходящего до патологии.

Эта группа детей имеет наименьшую выраженность алекситимии, тревоги, депрессии, перфекционизма, ригидности и наиболее позитивное самоотношение, они чаще других используют стратегии дистанцирования, планирования решения проблемы и позитивной переоценки.

Нами было отмечено, что у девочек с гармоничным пищевым поведением ситуативная тревога отрицательно коррелирует с самопринятием ( $r s=-0,573, p \leq 0,008)$, a личностная тревога положительно взаимосвязана с высокими стандартами в деятельности ( $r s=0,515, \mathrm{p} \leq 0,020)$ и отрицательно - с самопринятием ( $r s=-0,550, p \leq 0,012)$.

Следовательно, при высокой тревожности девочки с гармоничным пищевым поведением отличаются меньшим самопринятием. Вероятно, они осознают свою чрезмерную тревожность и интерпретируют её как негативное качество, с которым стремятся бороться. Тем самым тревожность выступает в качестве возможного фактора, снижающего самопринятие в этой группе дево- чек.

Усматривается взаимосвязь - чем больше у детей этой группы проявляется личностная тревожность, тем более высокими стандартами они задаются в своей деятельности. Вероятно, именно высокая личностная тревожность приводит к неадекватной оценке себя, что заставляет девочек ставить себе чрезмерно сложные цели, компенсируя таким образом чувство внутренней несостоятельности, обусловленное тревожностью.

\section{Выводы}

Представленное в настоящей работе эмпирическое исследование позволило выявить специфические особенности тревожности и эмоционально-личностной сферы у девочек пубертатного возраста с нарушением пищевого поведения. В процессе проведения исследования были выявлены различия особенностей тревожности личности у девочек с отклоняющимся и гармоничным пищевым поведением, а также установлены значимые корреляционные связи между особенностями тревожности и эмоционально-личностной сферой.

ЛИТЕРАТУРА

1. Прихожан А.М. Тревожность у детей и подростков: психологическая природа и возрастная динамика. - М.: Московский психолого-социальный институт; Воронеж: Издательство НПО «МОДЭК», 2000. - 304 с.

2. Е.Л. Солдатова, Г.Н. Лаврова Психология развития и возрастная психология. Онтогенез и дизонтогенез / Серия «Высшее образование». - Ростов н/Д: Феникс, 2004. - 384 с.

3. Кибитов А.О., Мазо Г.Э. Генетические исследования нарушений пищевого поведения: выход из замкнутого круга нозологической систематики //Социальная и клиническая психология - 2016.

4. Музыченко Г.Ф. Проективная методика «Несуществующее животное». Руководство и результаты психодиагностического исследования взрослых пациентов с различными расстройствами эмоционально-личностной сферы / Г.Ф. Музыченко. - СПб.: Речь, 2013. - 556 с.

5. Малкина-Пых И.Г. Терапия пищевого поведения / И.Г. Малкина-Пых. - М.: Эксмо, 2007. - 1040 с. - (Справочник практического психолога).

(c) Бакаева Елена Юрьевна (bakayeva_yelena@inbox.ru), Пилишвили Татьяна Сергеевна (pilishvili-ts@rudn.ru).

Журнал «Современная наука: актуальные проблемы теории и практики» 